\title{
Özel Okullarda Bilişim Teknolojileri (BT) Öğretmeni Olmak
}

\author{
Deniz ATAL \\ Ankara Üniversitesi, Eğitim Bilimleri Fakültesi, BÖTE Bölümü \\ atal@ankara.edu.tr \\ orcid.org/0000-0001-8030-9996 \\ Raziye SANCAR \\ Kırşehir Ahi Evran Üniversitesi, Eğitim Fakültesi, BÖTE Bölümü \\ raziye.sancar@ahievran.edu.tr \\ orcid.org/0000-0002-2875-9233
}

\begin{tabular}{lrr} 
Araştırma Makalesi & DOI: $10.31592 /$ aeusbed.684743 \\
\hline Geliş Tarihi: 04.02 .2020 & Revize Tarihi: 19.07 .2020 & Kabul Tarihi: 19.07 .2020
\end{tabular}

\section{Atıf Bilgisi}

Atal, D. ve Sancar, R. (2020). Özel okullarda bilişim teknolojileri (BT) öğretmeni olmak. Ahi Evran Üniversitesi Sosyal Bilimler Enstitüsü Dergisi, 6(2), 657-671.

ÖZ

Bu çalışma ile Bilgisayar ve Öğretim teknolojileri Eğitimi (BÖTE) bölümünden mezun olan ve özel okullarda Bilişim Teknolojileri (BT) Öğretmeni olarak görev yapan öğretmenlerin çalıştıkları kurumlarda görev ve sorumluluklarını, kurumların onlardan beklentilerini ve söz konusu bu çalışma ortamında öğretmenlerin mesleki anlamda kendilerini nasıl anlamlandırdıklarını belirlemek amaçlanmaktadır. Araştırmada nitel araştırma yaklaşımı benimsenmiş olup; farklı kurumlarda benzer ön koşullara sahip öğretmenler ve onların ortak deneyimlerinin incelenmesi durum çalışması biçiminde desenlenmiştir. Özel okulda görev yapan 18'i kadın (\%72), 7'si erkek (\%28) olmak üzere toplam 25 BT öğretmeninden, araştırmacılar tarafindan hazırlanan yapılandırılmış açık uçlu sorulardan oluşan anket formu ile veriler toplanmıştır. Yapılan araştırmada elde edilen veriler betimsel çözümleme ve içerik analizi ile çözümlenmiştir. Araştırmadan elde edilen verilere göre; özel okulda çalışan BT öğretmenleri okullarında Bilişim Teknolojileri ve Yazılım dersinden Teknoloji Tasarım derslerine kadar çok farklı derslere girmekte, hizmet içi eğitimler düzenlemekten, okulda etkinlik, yarışma ve proje yürütmeye kadar çok çeşitli görev ve sorumluluklar üstlenmektedirler. Yaşadıkları iş yoğunluğu nedeni ile BT öğretmenleri oldukça yıprandıklarını ve yorulduklarını vurgulamıştır. Araştırma sonunda, görev dışı sorumluluklar, kurumsal yapıdaki sorunlar, yönetimin ve ailelerin beklentileri, teknik olanaklar ve düşük maaş ödemeleri nedeni ile yaşadıkları sorunları dile getiren öğretmenlerin beklentileri ve mezun ya da mezuniyet aşamasında olan öğretmen adaylarına geleceğe yönelik önerileri tartışılmaktadır.

Anahtar Kelimeler: BT öğretmeni, özel okul, öğretmen eğitimi.

\section{Being an Information and Communication Technology (ICT) Teacher in Private School}

\begin{abstract}
Information and Communication Technology (ICT) teachers who are graduates of Computer Education and Instructional Technology (CEIT) program and work in private schools, their expectations from the private schools, and how they make sense of themselves as professionals. The Qualitative research approach was adopted in the research; The study of teachers with similar prerequisites and their common experiences in different institutions is designed as a case study. The data were collected from 25 ICT teachers 18 female (72\%) and 7 males (28\%) working in private schools with a questionnaire form consisting of structured open - ended questions prepared by the researchers. The data has been analyzed by using descriptive and content analysis approach. According to the data, the ICT teachers working in private schools take different courses from ITS to technology design courses in their schools and they undertake a variety of duties and responsibilities from organizing in-service pieces of training to conducting activities, competitions, and projects. For this reason, the ICT teachers working in private school have been exhausted and tired due to the intensity of their work. End of the study, expectations of these teachers who expressed their problems due to non-task responsibilities, low salary payments, technical facilities, institutional structure and expectations of management, and families have been shared, and suggestions have been discussed.
\end{abstract}

Keywords: ICT teacher, private school, teacher education.

\section{Giriş}

Eğitim Fakültelerinin 1997 yılında yeniden yapılanması ile birlikte fakülte bünyesinde Bilgisayar ve Öğretim Teknolojileri Eğitimi (BÖTE) bölümü kurulmuş ve bu bölümde öğretmen 
yetiştirilmeye başlanmıştır (YÖK, 1997). BÖTE bölümü mezunları, öncelikli olarak Milli Eğitim Bakanlığı'na (MEB) bağlı okullarda 2006 yılına kadar Bilgisayar dersini, 2012 yılına kadar Bilişim Teknolojileri dersini ve 2012 yılından sonra da Bilişim Teknolojileri ve Yazılım dersini yürüten Bilişim Teknolojileri (BT) öğretmeni olarak istihdam edilmektedir. Tablo 1'de 2013 yılından günümüze BÖTE bölümlerinden mezun olan öğretmen adayı sayıları ile MEB bünyesinde BT öğretmeni olarak istihdam edilen öğretmen sayıları yer almaktadır.

Tablo 1

Yıllara Göre BÖTE Bölümü Mezunlarının ve MEB'e Atanan Öğretmenlerin Sayısı

\begin{tabular}{ccc}
\hline Y11 & Mezun Say1s1 & MEB'e Atanan Öğretmen Say1S1 \\
\hline 2013 & 2326 & 1598 \\
2014 & 2991 & 1424 \\
2015 & 2912 & 1282 \\
2016 & 2284 & 1347 \\
2017 & 2015 & 420 \\
2018 & 2152 & 457 \\
2019 & 1 & 801 \\
Toplam & 14680 & 7329 \\
\hline
\end{tabular}

Tablo 1'e göre BÖTE bölümlerinden yılda ortalama 2500 öğretmen adayının mezun olduğu görülmektedir. 2016 yılına kadar mezun olan bu adayların yaklaşık \%43'ü MEB bünyesinde istihdam edilmiştir. Ancak 2017 yılı ve sonrasında MEB öğretmen atama uygulamalarındaki değişiklikler nedeni ile BT öğretmenleri özelinde bir yılda atanan öğretmen sayılarında radikal bir azalma olduğu dikkati çekmektedir. Hele ki atanan bu öğretmenlerin Talim Terbiye Kurulu Başkanlığı'nın (TTKB) 20.02.2014 tarihli ve 9 nolu "Öğretmenlik Alanları, Atama ve Ders Okutma Esasları" kararı temel alınarak 19 farklı bölüm mezunlarının olabileceği düşünüldüğünde, BÖTE bölümü mezunlarının MEB'e öğretmen olarak atanma olanaklarının daha da azaldığını söylemek yanlış olmayacaktır.

Yaşanılan bu istihdam sorunu BÖTE mezunu adaylarını farklı meslek arayışlarına yöneltmiştir. Adaylar lisans programında kazandıkları yeterliklerle özel sektörde donanım, yazılım, eğitim teknolojisi ve uzaktan eğitim gibi alanlarda çalışabilmekte, özel okullarda BT öğretmeni, teknoloji danışmanı, eğitim teknoloğu gibi çeşitli pozisyonlarda görev alabilmektedir (Akgün, Topal, ve Kıyıcı, 2019; Altun ve Ateş, 2008; Çakır, Çebi ve Özcan, 2013; Tosun, 2014). Çalışabilecekleri farklı meslek alanları olsa da özellikle öğretmenlik mesleğini sürdürmek isteyen adaylar için özel okullar önemli bir istihdam olanağı sağlamaktadır.

Özel okullar, 5580 sayılı Özel Öğretim Kurumları Kanununu temel alarak öğretmenlerin ücret ve diğer özlük haklarında düzenlemeler yapan (Mevzuat, 2007), rekabet yoğunluğunun yüksek olduğu eğitim kurumlarıdır. Bu kurumlarda öğretmenlik mesleği; kurumların istekleri, velilerin ve öğrencilerin beklentileri ile biçimlenmekte, öğretmenlerle her yıl yenilenen sözleşmelerle yürütülmektedir. Tablo 2'de ülkemizde özel okulların eğitim kademelerine göre güncel sayıları yer almaktadır.

Tablo 2

2018-2019 Ögretim Yılı Özel Ĕ̆itim Kurumlarının Kademelere Göre Toplam Okul Sayıları

\begin{tabular}{cc} 
Eğitim Kademesi & Okul/Kurum \\
\hline Okul öncesi eğitim & 5352 \\
İlkokul & 1808 \\
Ortaokul & 2060 \\
Ortaöğretim & 3589 \\
Örgün Eğitim & 12809 \\
\hline
\end{tabular}

\footnotetext{
${ }^{1}$ Tablo 1'de yer alan veriler YÖK'ün ve MEB'in güncel internet arşivlerinden erişilebilen veriler ile sınırlıdır. 2019 yılı verileri henüz güncellenmemiștir.
} 
Tablo 2'den de anlaşıldığı üzere, özel okullar ülkemizde her kademede oldukça yaygın olup, öğretmenlik mesleğini yürütmek isteyen BÖTE mezunu adaylar için önemli bir istihdam olană̆ sunmaktadır. Öte yandan, bu okullar BT öğretmenin "teknoloji lideri”, "değişim ajanı" ya da "yenileşme lideri" rollerini göz önünde bulundurarak (Devolder, Vanderlinde, Van Braak ve Tondeur, 2010; Lai ve Pratt, 2004; Tondeur, Cooper ve Newhouse, 2010) istihdam etmek istemektedirler. Çünkü pek çok özel okulun eğitim-öğretim etkinliklerinin merkezinde " 21 . yüzyıl becerileri doğrultusunda öğrencileri yaşama hazırlamak" bakış açısı yer almaktadır. 21. yüzyıl becerileri; eleştirel düşünme, problem çözme ve yaratıcılık gibi bilişsel becerileri, iletişim becerileri, sosyal beceriler, takım çalışması, kültürel duyarlılık ve zorluklarla başa çıkma gibi kişilerarası becerileri ve öz-yönetim, öz-düzenleme, zaman yönetimi, öz-gelişim, yaşam boyu öğrenme, uyarlanabilirlik gibi içsel/bireysel becerileri içermektedir (Kyllonen, 2012). Son yıllarda söz konusu olan bu becerilerin çağın gerektirdiği bilgiyi, aracı ve teknolojiyi uygun koşullarda kaynaştırarak eğitim öğretim süreçlerinde etkili kullanımı, BT öğretmenleri aracığı ile gerçekleşebilecektir. Dahası, özel okullar bu teknoloji ve araçların kullanımını rekabet alanına dönüştürmekte ve okullarının Kodlama, Robotik ve STEM (Science-Fen, Technology-Teknoloji, Engineering-Mühendislik, Mathematics-Matematik) gibi konularda yürüttükleri projelerle ön planda olmasını sağlamaktadırlar. Özel okullardaki bu rekabet yönelimi doğrudan alan uzmanı olan BT öğretmenlerinin istihdam durum ve koşullarına etki etmekte ve daha fazla okulda BT öğretmeni istihdama yol açmaktadır. İlgili alanyazın incelendiğinde, özel okul ve devlet okullarında çalışan alan öğretmenlerinin sahip oldukları özelliklerin ve çalışma koşullarının çeşitli değişkenler üzerinden incelendiği çalışmaların olduğu görülmektedir (Ballou ve Podgursky, 1998; Fidan ve Öztürk, 2015; Smith 1992; Sönmezer ve Eryaman, 2008; Xu ve Gulosino, 2006). Bu çalışmalarda özel okullarda çalışan öğretmenlerin özellikle düşük maaşlar, atran çalışma saatleri ve işyükleri nedeniyle streslerinin arttığı, yaşanılan sorunlarla birlikte başarımlarının, güdülenmelerinin, iş memnuniyetlerinin ve mesleği sürdürme ile ilgili kararlarının olumsuz etkilediği ortaya konulmuştur (Khan, Mateen, Hussain, Sohail ve Khan, 2017; Naidoo, 2019; Premalatha ve Subramanian, 2020). İlgili araştırmaların odağında genellikle sınıf öğretmenleri yer almakta olup, özel okullarda çalışan BT öğretmenleri özelinde alanyazında yapılmış bir çalışmanın olmadığı dikkati çekmektedir. Halbuki özel okullarda çok fazla istihdam edilen BT öğretmenlerinin yaşadıkları sorunlar ayrıntılı bir biçimde incelendiğinde, onların gözünden özel okullarda BT öğretmeni olmanın anlamı net bir biçimde ortaya konulabilir, elde edilen sonuçlar gelecekte özel okullarda çalışmak isteyen öğretmen adaylarına yol gösterebilir.

\section{Araştırmanın Amacı}

Bu çalışma ile BÖTE bölümünden mezun olan ve özel okullarda BT öğretmeni olarak görev yapan öğretmenlerin çalıştıkları kurumlarda görev ve sorumluluklarını, kurumların onlardan beklentilerini ve söz konusu bu çalışma ortamında öğretmenlerin mesleki anlamda kendilerini nasıl anlamlandırdıklarını belirlemek amaçlanmaktadır. Böylece özel okullarda BT öğretmeni olarak çalışmanın ne anlama geldiğine yönelik bir çerçevenin çizilebileceği düşünülmektedir.

\section{Yöntem}

Araştırmada nitel araştırma yaklaşımı benimsenmiş olup; farklı kurumlarda benzer ön koşullara sahip ögretmenler ve onların ortak deneyimlerinin çalışılması durum çalışması olarak desenlenmiştir. "Durum" tek bir kişi, birden fazla birey (birlikte ya da bireysel), bir program, bir olay/etkinlik ya da bir dizi etkinlikten oluşan çeşitli aşamalar içeren bir süreci kapsayabilmektedir (Creswell, 2011).

\section{Çalışma Grubu}

Araştırmaya 18'i kadın (\%72), 7'si erkek (\%28) olmak üzere toplam 25 BT öğretmeni katılmıştır. Çalışma grubu oluşturulurken kolay ulaşılabilir amaçlı örnekleme yöntemi kullanılmıştır. Araştırmaya katılan BT öğretmenlerinin demografik özellikleri Tablo 3’te yer almaktadır. 
Tablo 3

Çalışma Grubunun Oluşturan BT Öğretmenlerinin Demografik Özellikleri

\begin{tabular}{cccc}
\hline Demografik Özellikler & & $\mathrm{f}$ & $\%$ \\
\hline \multirow{2}{*}{ Yaş } & $23-25$ & 11 & 44 \\
& $26-28$ & 7 & 28 \\
& 29 ve daha fazla & 7 & 28 \\
\hline \multirow{3}{*}{ Mesleki Kıdem } & 1 yıl & 6 & 24 \\
& $2-5$ y1l & 13 & 52 \\
& $6-10$ yıl & 2 & 8 \\
\multirow{2}{*}{ Öğrenim Durumu } & 11 yıl ve daha fazla & 4 & 80 \\
& Lisans & 20 & 20 \\
\hline
\end{tabular}

Tablo 3 incelendiğinde, araştırmaya katılan BT öğretmenlerinin büyük çoğunluğunun 23-25 yaş aralığında olduğu (\%44) ve meslek kıdemlerinin 2-5 yıl arasında değiştiği (\%52) görülmektedir. Mesleki kıdemi 6 yıl ve daha fazla olan BT öğretmenlerinin sayısı ise oldukça azdır (\%24). Araştırmaya katılan BT öğretmenlerinin mezuniyet durumları incelendiğinde; \%80'inin lisans mezunu, \%20'sinin ise yüksek lisans mezunu olduğu görülmektedir.

\section{Veri Toplama}

Araştırmanın katılımcılara kolay ulaşılabilir durum örneklemesi yöntemi kullanılarak erişilmiş olup, veriler araştırmacılar tarafindan hazırlalan çevrimiçi görüş formu aracılığı ile toplanmıştır. Veri toplama süreci 2018-2019 yılları arasında yürütüldügünden araştırma sürecinde etik kurul izni alınmamıştır. Ancak araştırmada katılımcılara katılımın gönüllülük esasına dayalı olduğu, soruların hepsini yanıtlama zorunluluklarının olmadığı ve istedikleri zaman araştırma sürecinden çıkabileceklerine ilişkin ayrıntılı açıklamalarda bulunulmuştur. Tüm bu açıklamaların ardından katılıma gönüllü olan öğretmenlere formlar gönderilmiştir. Araştırmada kullanılan ölçme aracı olan çevrimiçi görüş formu, "Çalıştığınız okulda okul yönetiminin sizden beklediği görev ve sorumluluklar nelerdir?", "Mesleğinizle ilgili hiçbir bilgisi olmayan kişiye özel okulda yaptığınız işi nasıl anlatırsınız/tanımlarsınız?", “Özel okulda çalışmak isteyen BT öğretmen adaylarına önerileriniz nelerdir", biçiminde açık uçlu sorulardan oluşmaktadır.

\section{Verilerin Analizi}

Nitel araştırma yaklaşımının benimsendiği araştırmalarda verilerin analizi; analiz için verilerin hazırlanması ve düzenlenmesi, kodların oluşturulması, temalara ayrılması ve verilerin sunulması aşamalarını içermektedir (Creswell, 2007). Araştırmada elde edilen veriler ile betimsel çözümlemeler yapılmış olup; söz konusu çözümleme süreçleri ardışık olarak izlenmiştir. Çözümleme iki ayrı araştırmacı tarafindan eş zamansız yapılmış olup; ardından yapılan yüz yüze tartışma oturumunda kod ve temalara son hali verilmiştir.

\section{Bulgular}

$\mathrm{Bu}$ bölümde bulgular, veri toplama aracındaki sorular temel alınarak alt başlıklar halinde sunulmuştur.

\section{BT Öğretmenlerinin Çalıştıkları Kurumların Özellikleri ve bu Kurumlarda Çalışma Koşulları} almaktadır.

Araştırmaya katılan BT öğretmenlerinin özel okullardaki çalışma koşulları Tablo 4'te yer 
Tablo 4

BT Öğretmenlerinin Özel Okullardaki Çalışma Koşulları

\begin{tabular}{lccc}
\hline Değişken & $\mathrm{n}$ & $\mathrm{f}$ & $\%$ \\
\hline Aynı kurumdaki görev süresi & 1 yıldan az & 7 & 28 \\
& $1-2$ yıl arası & 9 & 36 \\
& 2 yıl ve daha fazla & 9 & 36 \\
\hline Günlük ortalama çalışma saati & 8 saatten az & 4 & 16 \\
& 8 saat & 13 & 52 \\
& 8 saatten fazla & 8 & 32 \\
\hline Haftada çalışılan gün sayısı & 4 gün & 1 & 4 \\
& 5 gün & 11 & 44 \\
& 6 gün & 13 & 52 \\
\hline Aylık ortalama maaş & $1500-2000$ & 2 & 8 \\
& $2000-3000$ & 10 & 40 \\
\end{tabular}

Tablo 4 incelendiğinde, BT öğretmenlerinin yarısından fazlasının 1 yıldan az (\%28) ya da 1-2 yıl süreyle (\%36) aynı okullarda çalıştıkları görülmektedir. 2 yıldan fazla süreyle aynı okulda çalışan BT öğretmenlerinin görece azlığı dikkati çekmektedir (\%36). BT öğretmenlerinin özel okullarda çalıştıkları gün ve saatler incelendiğinde, BT öğretmenlerinin yarısından fazlasının (\%52) haftada 6 gün, günde ise 8 saat çalıştığı görülmektedir. Günde 8 saatten az çalışan BT öğretmenlerinin sayısı oldukça azdır (\%16). Öte yandan, Tablo 2'ye göre 4000 TL ve üzeri maaş alan BT öğretmeni neredeyse hiç yokken (\%4), yaklaşık yarısı (\%48) aylık 3000 TL ve altında maaş almaktadır.

Özel okullarda çalışan BT öğretmenlerinin çalıştıkları kurumların teknik ve alt yapı özellikleri Tablo 5'te yer almaktadır.

Tablo 5

BT Öğretmenlerinin Çalıştıkları Özel Okulların Özellikleri

\begin{tabular}{|c|c|c|c|}
\hline Tema & Kod & $\mathrm{f}$ & $\%$ \\
\hline \multirow{3}{*}{ Sınıflardaki öğrenci sayısı } & 6-14 öğrenci & 2 & 8 \\
\hline & 15-19 öğrenci & 8 & 32 \\
\hline & 20-25 öğrenci & 15 & 60 \\
\hline \multirow{3}{*}{ BT sınıflarındaki bilgisayar sayısı } & $6-14$ bilgisayar & 2 & 8 \\
\hline & 15-19 bilgisayar & 4 & 16 \\
\hline & $20-25$ bilgisayar & 19 & 76 \\
\hline \multirow{6}{*}{ Okulun teknik olanakları } & BT sinıfı & 25 & 100 \\
\hline & Arduino setleri & 19 & 76 \\
\hline & Etkileşimli tahtalar & 10 & 40 \\
\hline & $3 \mathrm{~d}$ yazıcı & 9 & 36 \\
\hline & STEM sinıfı & 4 & 16 \\
\hline & Lego Ev3 & 3 & 12 \\
\hline
\end{tabular}

Tablo 5 incelendiğinde, özel okullarda çalışan BT öğretmenlerinin yarısından fazlasının (\%60) sınıflarında ortalama 20-25 öğrencisi olduğu ve okullarında daha kalabalık sınıfların bulunmadığı dikkati çekmektedir. BT sınıflarındaki bilgisayar sayılarının ise her öğrenciye bir bilgisayar düşecek biçimde düzenlendiği görülmektedir.

Tablo 5 de dikkati çeken bir diğer bulgu, okulların teknik olanakları ile ilgilidir. Tablo 3'e göre, her okulda BT sınıfı bulunmakta olup, bazılarında (\%16) BT sınıfinın yanı sıra STEM sınıfları da bulunmaktadır. Öte yandan, söz konusu özel okulların \% 76 'sında kodlama eğitiminde kullanılan Arduino setleri kullanılmaktadır. Buna karşın, etkileşimli tahtalar (\%40), 3D yazıcılar (\%36) ve Legolar (\%12) gibi son dönemde özellikle özel okullarda adlarının çok fazla geçtiği yeni teknoloji ve uygulama sayılarının görece azlığı dikkati çekmektedir. 


\section{BT Öğretmenlerinin İstihdam Biçimleri, Verdikleri Dersler, Görev ve Sorumlulukları}

BT öğretmenlerinin kurumlarındaki istihdam biçimi, ders verdikleri sınıf düzeyleri ve verdikleri dersler Tablo 6'da yer almaktadır. Tablo 6 incelendiğinde, BT öğretmenlerinin yarısından fazlasının (\%64) okullarda BT öğretmeni olarak istihdam edildiği, ancak BT formatör öğretmeni (\%24) ya da yazılım ve robotik kodlama öğretmeni (\%12) olarak da işe alındıkları dikkati çekmektedir.

Tablo 6

Özel Okullarda Çalışan BT Öğretmenlerinin İstihdam Biçimleri, Ders Verdikleri Sınıf Düzeyleri ve Verdikleri Dersler

\begin{tabular}{llcc}
\hline Tema & Kod & $\mathrm{f}$ & $\%$ \\
\hline BT öğretmenlerinin istihdam & BT Öğretmeni & 16 & 64 \\
biçimleri & BT Formatör Öğretmeni & 6 & 24 \\
& Yazılım ve Robotik Kodlama Öğretmeni & 3 & 12 \\
\hline BT öğretmenlerinin verdiği dersler & BTY Dersi & 22 & 88 \\
& Robotik ve Kodlama Dersi & 7 & 28 \\
& Bilgisayar Bilimi Dersi & 3 & 12 \\
& STEM Dersi & 3 & 12 \\
& Demokrasi ve İnsan Hakları Dersi & 1 & 4 \\
& Teknoloji Tasarım & 1 & 4 \\
\hline Derslerine girdiğiniz sinıf düzeyleri & Anasinıfi, İlkokul ve Ortaokul & 11 & 44 \\
& İlkokul ve Ortaokul & 8 & 32 \\
& Ortaokul & 3 & 12 \\
& Lise & 3 & 12 \\
\hline
\end{tabular}

Öte yandan, Tablo 6'ya göre bu öğretmenlerin okullarda en fazla BTY dersine girdikleri (\%88), bunun yanı sira Robotik ve Kodlama dersi (\%28), Bilgisayar Bilimi dersi (\%12), Demokrasi ve İnsan Hakları (\%4) ve Teknoloji Tasarım (\%4) gibi derslere de girdikleri görülmektedir. Öte yandan, BT öğretmenlerinin okullarda ders verdikleri sınıf düzeylerinin ise çeşitlilik gösterdiği dikkati çekmektedir. Tablo 6'ya göre BT öğretmenlerinin yaklaşık yarısı (\%44) aynı eğitim öğretim döneminde anasınıfından ortaokula kadar tüm düzeylerde derslere girmektedir.

Özel okullardaki okul yönetiminin ve diğer öğretmenlerin BT öğretmenlerinden istek ve beklentileri göz önünde bulundurulduğunda, BT öğretmenlerinin okullarda üstlendikleri görev ve sorumluluklar Tablo 7'de yer almaktadır.

Tablo 7

BT Öğretmenlerinin Okullarda Üstlendikleri Görev ve Sorumluluklar

\begin{tabular}{|c|c|c|c|}
\hline Tema & Kod & $\mathrm{f}$ & $\%$ \\
\hline \multirow{6}{*}{$\begin{array}{l}\text { Eğitim-Öğretim ile } \\
\text { İlgili }\end{array}$} & Sorumlu olduğu/olmadığı derslere girmek & 25 & 100 \\
\hline & Diğer derslerdeki teknoloji entegrasyonuna destek olmak & 14 & 56 \\
\hline & Öğrenciler için kurs açmak & 6 & 24 \\
\hline & Komisyonlarda/kulüplerde aktif görev almak & 4 & 16 \\
\hline & Hizmetiçi eğitimlere katılmak & 5 & 20 \\
\hline & Sinıf rehber öğretmenliği yapmak & 3 & 12 \\
\hline \multirow{7}{*}{$\begin{array}{l}\text { Teknik Destek ile } \\
\text { İlgili }\end{array}$} & BT sınıfındaki teknik-altyapı sorunlarını çözmek & 18 & 72 \\
\hline & Okuldaki etkinliklerde altyapı desteği sunmak & 15 & 60 \\
\hline & Okuldaki diğer öğretmenlere teknik destek sağlamak & 9 & 36 \\
\hline & Okulun internet sitesini güncellemek & 7 & 28 \\
\hline & Etkinlik ve özel günler için görsel tasarım yapmak & 5 & 20 \\
\hline & Okulun sosyal medya hesaplarını kontrol etmek & 5 & 20 \\
\hline & Okuldaki etkinliklerde fotoğraf çekmek & 3 & 12 \\
\hline \multirow{3}{*}{ Diğer } & Okulda etkinlik, proje ve yarışma düzenlemek & 19 & 76 \\
\hline & Aylık okul dergisini düzenlemek & 4 & 16 \\
\hline & Nöbet tutmak & 3 & 12 \\
\hline
\end{tabular}


Tablo 7 incelendiğinde, BT öğretmenlerinin okuldaki görev ve sorumluluklarının, özel okullarda eğitim-öğretim ile ilgili, teknik destek ile ilgili ve diğer işlerle ilgili olarak üç ayrı tema altında toplandığı görülmektedir. BT öğretmenlerinin eğitim ve öğretim ile ilgili görev ve sorumlulukları arasında en fazla derslere girmek (\%100), teknoloji entegrasyonunu desteklemek (\%56) ve öğrencilere kurs açmak (\%24) yer almaktadır. Teknik destek sağlamak ile ilgili olarak BT öğretmenlerinin da en fazla teknik-altyapı sorunlarını çözmek (\%72), etkinliklere altyapı desteği sağlamak (\%60) ve öğretmenlere teknik destek sağlamak (\%36) biçiminde sorumlulukları olduğu göze çarpmaktadır. Bu iki boyut dışında BT öğretmenlerine okullarda etkinlik, proje ve yarışma düzenlemek (\%76) ve okul dergisi hazırlamak (\%16) gibi görev ve sorumluluklar da verilmektedir.

\section{Velilerin ve Öğrencilerin BT Öğretmenlerinden İstek ve Beklentileri}

BT öğretmenlerinin görev ve sorumlulukları okul yönetiminin ve diğer öğretmenlerin istek ve beklentileri ile sınırlı değildir. Velilerin ve öğrencilerin istek ve beklentileri de onların görev ve sorumluluklarını arttırmaktadır. Tablo 8'de veli ve öğrencilerin BT öğretmenlerinden beklentileri yer almaktadir.

Tablo 8

Velilerin ve Öğrencilerin BT Öğretmenlerinden İstek ve Beklentileri

\begin{tabular}{|c|c|c|c|}
\hline & & $\mathrm{f}$ & $\%$ \\
\hline \multirow{4}{*}{$\begin{array}{l}\text { Velilerin } \\
\text { beklentileri }\end{array}$} & $\begin{array}{l}\text { Çocuklarının güncel/popüler teknoloji bilgisine sahip olmalarının } \\
\text { sağlanması }\end{array}$ & 14 & 56 \\
\hline & Çocuklarının teknolojiyi doğru ve etkili kullanmalarının sağlanması & 13 & 52 \\
\hline & Çocuklarının teknoloji bağımlılığından korunmalarının sağlanması & 8 & 32 \\
\hline & $\begin{array}{l}\text { Çocuklarının daha fazla kodlama ve robotik etkinliklerine ve } \\
\text { yarışmalarına katılmalarının sağlanması }\end{array}$ & 8 & 32 \\
\hline \multirow{4}{*}{$\begin{array}{l}\text { Öğrencilerin } \\
\text { beklentileri }\end{array}$} & Derslerde daha fazla etkinlik ve uygulama yapmak & 13 & 52 \\
\hline & Daha fazla projelere ve yarışmalara katılmak & 11 & 44 \\
\hline & Ders saatlerinde oyun oynayabilmek ve serbest kalabilmek & 10 & 40 \\
\hline & Daha fazla kodlama ve robotik eğitimi almak & 3 & 12 \\
\hline
\end{tabular}

Tablo 8 incelendiğinde özel okullarda çocukları okuyan velilerin yarısından fazlası (\%56) çocuklarının güncel ve popüler olan teknoloji bilgisine sahip olmalarını ve teknolojiyi doğru ve etkili kullanmalarını (\%52) istemektedir. Öğrenciler ise daha çok derslerdeki uygulamalara odaklanmakla birlikte, daha fazla etkinlik yapmayı (\%52) ve daha fazla proje ve yarışmalara katılmayı (\%44) istemektedir.

\section{Özel Okullarda Çalışan BT Öğretmenlerinin Kendilerini Tanımlama Biçimleri}

Tablo 9'da özel okullarda çalışan BT öğretmenlerinin üstlendikleri görev ve sorumlulukları göz önünde bulundurarak çalıştıkları kurumlarda kendilerini nasıl tanımladıklarına ilişkin bulgular yer almaktadır.

Tablo 9

Özel Okullarda Çalışan BT Öğretmenlerinin Kendilerini Nasıl Tanımladıkları

\begin{tabular}{lcc}
\hline Kod & f & $\%$ \\
\hline Kodlama ve robotik uygulamaları öğreten öğretmen & 18 & 72 \\
BİT'in doğru, bilinçli ve etkili kullanımını öğreten öğretmen & 15 & 60 \\
Teknolojiyi araştıran, tasarlayan ve üreten öğrenciler yetiştiren öğretmen & 9 & 36 \\
Okulun joker eleman1-ara elemanı & 7 & 28 \\
Öğrencilere ve öğretmenlere rehberlik eden öğretmen & 7 & 28 \\
21. yy becerilerini kazandıran öğretmen & 6 & 24 \\
Teknik işlerden sorumlu eleman & 5 & 20 \\
Proje yöneticisi & 5 & 20 \\
Öğrencileri gerçek yaşama hazırlayan öğretmen & 4 & 16 \\
Yaratıcı ve yenilikçi teknolojik ürünler ortaya koyan öğretmen & 3 & 12 \\
\hline
\end{tabular}


Tablo 9 incelendiğinde, BT öğretmenlerinin kendilerini yeni teknolojilerle birlikte gelen kazanımları ve uygulamaları eğitim öğretim sürecine kaynaştırma odaklı tanımladıkları görülmektedir. Tablo 9 incelendiğinde, BT öğretmenlerinin kendilerini BT öğretmeni yerine en fazla kodlama ve robotik uygulamaları öğreten öğretmen (\%72) ve BİT'in doğru, bilinçli ve etkili kullanımını öğreten öğretmen (\%60) olarak tanımladıkları dikkati çekmektedir. Öte yandan, öğretmenlik mesleği dışında kendini ara eleman (\%28), teknik sorumlu (\%24), proje yöneticisi (\%20) gibi gören öğretmenlerin sayılarının azımsanmayacak derecede olduğu dikkati çekmektedir.

\section{Özel Okullarda Çalışan BT Öğretmenlerinin Yaşadıkları Sorunlar ve Aday Öğretmenlere Öneriler}

Özel okullarda çalışan BT öğretmenlerinin kurumlarında yaşadıkları sorunlar ve adaylara önerileri Tablo 10'da yer almaktadır. Tablo 10'da, söz konusu öğretmenlerin kurumsal yapıdan ve üstlendikleri sorumluluklardan kaynaklı sorunları yer almaktadır. Bu öğretmenlerin kurumsal yapıdan kaynaklı yaşadıkları sorunlar incelendiğinde, en fazla özel okula çocuklarını gönderen velilerin istek ve beklentilerinden (\%32), kurumdaki donanım eksikliğinden (\%24) ve kurumlarında kendilerini öğretmen olarak hissedememekten kaynaklı (\%16) sorunlar yaşadıkları görülmektedir. Bu öğretmenler yaşanılan sorunlar nedeni ile gelecek yıl aynı okulda çalışmak istememektedir.

Tablo 10

BT Öğretmenlerinin Özel Okullarda Yaşadıkları Sorunlar (Bir sonraki yıl aynı kurumda çalışmak isteme durumlarl)

\begin{tabular}{|c|c|c|c|c|}
\hline & Tema & Kod & $\mathrm{f}$ & $\%$ \\
\hline \multirow{9}{*}{ 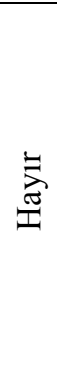 } & \multirow{6}{*}{$\begin{array}{c}\text { Kurumsal Yapidan } \\
\text { Kaynaklanan }\end{array}$} & Velilerin istek ve beklentileri & 8 & 32 \\
\hline & & Kurumdaki donanım eksikliği & 6 & 24 \\
\hline & & Okulda kendini öğretmen gibi hissetmeme & 4 & 16 \\
\hline & & Kurumda sağlanan teknik destek eksikliği & 4 & 16 \\
\hline & & Öğrenci değerlendirmelerinin nesnel olamaması & 3 & 12 \\
\hline & & Okulda değer görmediğini hissetme & 3 & 12 \\
\hline & Yüklenen Görev ve & İş yükünün yoğun olması & 19 & 76 \\
\hline & Sorumluluklardan & Meslekle ilgisiz görev ve sorumlulukların fazla olması & 18 & 72 \\
\hline & Kaynaklanan & Maaşların çalışma koşullarına uygun olmaması & 15 & 60 \\
\hline \multirow{4}{*}{$\sum_{\text {立 }}^{+}$} & \multirow{3}{*}{$\begin{array}{l}\text { Kurumsal Yapidan } \\
\text { Kaynaklanan }\end{array}$} & Çalıştıkları kurumda düzeni kurmuş olma & 5 & 20 \\
\hline & & Okulun akademik başarısı/saygınlığı & 2 & 8 \\
\hline & & Çalıştığ 1 kurumu sevme & 1 & 4 \\
\hline & $\begin{array}{c}\text { Gelecek Endişesinden } \\
\text { Kaynaklanan }\end{array}$ & Yeni iş bulamama endişesi & 8 & 32 \\
\hline
\end{tabular}

Aynı okulda çalışmak istemeyen BT öğretmenlerinin kurumlarındaki görev ve sorumluluklarla ilgili yaşadıkları sorunlar incelendiğinde ise, en fazla yoğun iş yüklerinin $(\% 76)$, meslek ile ilgisiz görev ve sorumluluklarının olması (\%72) ve çok çalışmalarına karşın aldıkları düşük maaşların (\%60) onları başka bir iş aramaya yönlendirdiği belirlenmiştir.

Öte yandan, Tablo 10, BT öğretmenlerinin bir kısmının gelecek yıl aynı kurumda çalışmaya devam etmeyi istediklerini göstermektedir. Alınan bu karar üzerinde kurumsal yapı ve gelecek kaygıs1 etkin rol oynamaktadır. Söz konusu BT öğretmenleri, çalıştıkları kurumda düzenlerini kurdukları için (\%20) aynı kurumda çalışmaya devam etmek istemektedirler. Burada dikkati çeken en önemli nokta, BT öğretmenlerinin \%32'si kurumlarında mutlu olmadıkları halde yeni iş bulma endişesi nedeni ile aynı kurumda çalışmaya devam etmek istediklerini belirtmektedirler.

BT öğretmenlerinin özel okulda çalışmak isteyen BT öğretmen adaylarına bir takım önerileri bulunmaktadır. Bu öneriler Tablo 11'de yer almaktadır. 
Tablo 11

BT Ö̈̆retmenlerinden BT Öğretmen Adaylarına Öneriler

\begin{tabular}{|c|c|c|c|}
\hline Tema & Kod & $\mathrm{f}$ & $\%$ \\
\hline \multirow[b]{2}{*}{ Alanda Uzmanlık Geliştirmek } & Alanla ilgili teknolojik gelişmeleri yakından takip etmeliler & 15 & 60 \\
\hline & $\begin{array}{l}\text { İşe başlamadan önce teknik ve mesleki olarak kendilerini iyi } \\
\text { geliştirmeliler }\end{array}$ & 9 & 36 \\
\hline \multirow{4}{*}{$\begin{array}{l}\text { Kurumsal Süreçler Hakkında } \\
\text { Farkındalık Oluşturmak }\end{array}$} & Özel okulda çalışmanın zorluklarını bilmeliler & 12 & 48 \\
\hline & $\begin{array}{l}\text { Sürecin en başında kurumdaki görev ve sorumluluklarını } \\
\text { belirlemeliler }\end{array}$ & 8 & 32 \\
\hline & Kamuya atanabilmek için daha fazla çalışmalılar & 7 & 28 \\
\hline & $\begin{array}{l}\text { Kurumsal ve teknolojik altyapısı sağlam kurumları tercih } \\
\text { etmeliler }\end{array}$ & 4 & 16 \\
\hline \multirow{4}{*}{ Bireysel Özellikler } & Görevlerini düzgün yapmalı ve planlı olmalılar & 5 & 20 \\
\hline & Öğretmenlik mesleğini seviyorlarsa sürdürmeliler & 5 & 20 \\
\hline & Sabırlı ve azimli olmalılar & 4 & 16 \\
\hline & Ne istediklerini belirlemeliler & 4 & 16 \\
\hline
\end{tabular}

Tablo 11 incelendiğinde, BT öğretmenlerinin özel okullarda çalışmak isteyen BT öğretmen adaylarına alanda uzmanlık geliștirmeleri, kurumsal süreçler hakkında farkındalık geliștirmelerinin yanı sıra bireysel özelliklerini dikkate alarak çeşitli önerilerde bulundukları görülmektedir. Söz konusu öneriler arasında en çok alandaki değişimleri takip etmeleri (\%60), özel okulda çalışma koşullarının zorluğunun farkında olmaları (\%48), mesleğe başlamadan önce kendilerini iyi hazırlamaları/yetiştirmeleri (\%36), kurumda çalışmaya başlamadan okul yöneticileriyle birlikte tüm görev ve sorumluluklarını belirlemeleri (\%32) dikkati çekmektedir. Bunlar dışında BT öğretmenleri BT öğretmen adaylarına görevlerini yaparken planlı olmaları (\%20), mesleği seviyorlarsa sürdürmeleri (\%20) ve sabırlı olmaları (\%16) konularında da çeşitli önerilerde bulundukları görülmektedir.

\section{Sonuç, Tartışma ve Öneriler}

Öğretmenlik mesleği; yaratıcılık ve karar alma süreçleri ile biçimlenen, pek çok görev ve sorumluluğun yürütüldüğü, son derece zorlu ve karmaşık bir meslektir (Day, Fernandez, Hauge ve Muller, 2000). Gelecek nesillerin yaşamlarını biçimlendirme ve dönüştürme gücünü elinde tutan bu profesyonel meslekte özel okullar; mezun sayısındaki yoğunluk ve devlet okullarında mezunlar için yeterli istihdam olanağ 1 bulunmaması nedeniyle alternatif bir kariyer olanağ çekmektedir (Green, Machin, Murphy ve Zhu, 2008). BT öğretmenliği özelinde de durum farklı değildir. Bugün devlet okullarındaki BT öğretmeni arzının BT öğretmeni talebinden daha yüksek olduğu düşünüldüğünde, özel okulların varlığı BT öğretmenleri için de alternatif çalışma alanları oluşturmaktadır. Ancak, bilinen o ki özel okullar; çalışma koşulları, istihdam biçimleri, öğrenciye ve öğretmene sunduğu olanaklar ve öğretmenlerden beklentiler gibi boyutlarda devlet okullardan oldukça farklılaşmaktadır. Green ve diğerlerine (2008) göre özel okulda çalışmak isteyen öğretmenlerin sektöre özgü bir takım farkındalığa ve becerilere sahip olması gerekmektedir.

Yapılan araştırmaya göre özel okulda BT öğretmeni,

- Birbirinden farklı ve güncel konu/içerik bilgisine sahip,

- Bu konu ve içeriklerin öğretiminde yetkin,

- Kendini sürekli geliştiren,

- Söz konusu güncel konularda ders dışı etkinlik/kurs/projelerin tasarlanması ve yürütülmesinden sorumlu,

- BT öğretmenliği dışında yazılım ve kodlama ya da STEM öğretmenliği gibi başka kadrolar için de istihdam edilebilen,

- Çalıştıkları kurumlarda diğer öğretmenlere rehberlikten okula teknik destek hizmeti sunmaya kadar pek çok görevi üstlenerek yoğun iş yükü ve çalışma koşullarında çalışan,

- Teknik olanakları görece yeterli, kalabalık olmayan sınıflarda derslerini işleyen,

- Okul yönetiminin beklentilerinin yanı sıra velilerin beklentilerini de karşılayan, 
- Yapılan işte maddi ve/veya manevi yeterli doyuma erişemeyebilen bir profesyonel olarak görülmektedir.

Elde edilen bu sonuçlar, özel okullarda çalışan BT öğretmenlerinin devlet okullarında çalışanlara göre yenilikleri daha fazla takip etmesini, değişime açık olmasını, projelerle ve yarışmalarla okulu daha görünür ve popüler tutmasını, okul yönetimi ile velileri de memnun etmesini gerektirmektedir. Tüm bunları yaparken devlet okullardakine benzer biçimde öğretmenlik dışında üstlendikleri görev ve sorumluluklar nedeni ile kendilerini öğretmen gibi hissedemedikleri, maddi olarak yeterince tatmin olmadıkları ve çaresizlik içinde mesleklerini sürdürdükleri belirlenmiştir. BT öğretmenleri ile ilgili alanyazında yapılan araştırmalar incelendiğinde, ne yazık ki özel okullarda yaşanılan bu sorunların yalnızca özel okullardaki BT öğretmenlerine özgü bir sorun olmadığ1 görülmektedir (Atal-Köysüren ve Deryakulu, 2017; Deryakulu, 2015; Dursun ve Saracaloğlu, 2016; Eren ve Uluuysal, 2012; Yeşiltepe ve Erdoğan, 2013). Devlet okullarından farklı olarak, özel okullarda çalışan BT öğretmenlerinin son yıllarda iyice popüler olan 21. yy. becerilerinin öğretimi, kodlama eğitimi, robotik uygulamalar ve STEM uygulamaları ile iş yüklerinin daha da arttığı, uzmanlık alanların ve görev tanımlarının okullarda yaşanan dönüşümle birlikte değiş̧meye başladığı düşünülmektedir. İlk bakışta özel okulların sağladığı altyapı ve teknolojik olanaklar açısından devlet okullarına göre olanaklarının fazla olduğu düşünülse de araştırmaya katılan BT öğretmenlerinin teknoloji yetersizlikleri dile getirmiş olması bu okulların bile teknoloji sağlama konusunda pek çok eksiğinin olabileceğini göstermektedir.

Özel okullarda çalışan BT öğretmenlerinin yaşadığı tüm bu sorunlar, verdikleri dersler, yürüttükleri projeler ve diğer sorumluluklar göz önünde bulundurulduğunda, BT öğretmenleri için özel okullarda çalışmak hiç de kolay değildir. Bu noktada hem adayların öğretmen eğitimi sürecinde bilinçlenmesine hem de mesleği sürdüren BT öğretmenlerinin mesleki gelişimleri için desteklenmesine gereksinim olduğu düşünülmektedir. Bilinen o ki, BÖTE bölümü öğrencilerinin mesleklerine ilişkin zihinleri hala karışık, kendilerini mesleki anlamda yeterli hissedememekte, gelecekleri ile ilgili olarak kendi yollarını net bir biçimde çizememekte ve bu yüzden mesleki kaygı yaşamaktadır (Atal, 2019; Eşel, Kaya, Kurt ve Ünal, 2012; Karataş, 2010; Kurtoğlu ve Seferoğlu, 2012). Gerek öğretmen adaylarının gerekse BT öğretmenlerinin yaşadıkları zorluklar ve mesleki kaygıları göz önüne alındığında, temel sorunun adayların öğretmen eğitimini sürecinde yeterince bilinçli bir biçimde yetişirilememesinden kaynaklandığı düşünülmektedir. Güneş ve Uygun'da (2016) öğretmen adaylarının öğretmen eğitimi sürecince öğrendiklerini uygulayama aktaramadıklarını ve öğretmenlik becerilerini yeterince geliştiremedikleri için meslek yaşantılarında sorun yaşadıklarını belirlemişlerdir. Özellikle mesleğin ilk yıllarında öğretmenlerin mesleki sorun ve hatalarının önüne geçebilmek için öğretmenlere lisans ve adaylık eğitimlerinde hataları en aza indirecek nitelikte rehberlik yapılması önemli görülmektedir (Atmaca, 2020).

2018 yılında yenilenen BÖTE lisans programın dersleri ve içerikleri incelendiğinde, BT öğretmeninin özlük hakları, istihdam olanakları, BT öğretmenlerini doğrudan ilgilendiren politikalar ve uygulamalarla ilgili bilgilerin sunulduğu ders kazanımlarına rastlanmamıştır. Kimi alan bilgisi ve meslek bilgisi derslerinde öğretim üyeleri öğrencileri bilgilendirmek için çeşitli çalışmalar yapsa da görünen o ki bu bilgilendirme yeterli olmamaktadır. Bu noktada, BT öğretmen adaylarının yaşadıkları zihin karışıklığını ortadan kaldırmak, olumsuz duygu durumlarını azaltmak ve bilinçli ve yetişmiş bir biçimde meslek yaşantılarına başlamalarını sağlamak için öğretmenlik uygulaması derslerinin kuramsal kısmı daha etkili kullanılabilir. Örneğin, bu derste özel okullardaki çalışma koşullarını, öğretmenlerin sosyal statüsünü ve devlet ve özel okullarda yaşanılan zorlukları içeren konular tüm gerçekliği ile sunulabilir. Topluma hizmet uygulamaları dersi kapsamında özel okullarla iş birliği sağlanarak adaylar okullarda yürütülen projeleri, uygulamaları ve BT öğretmenlerini yerinde gözlemleyebilir, projelerde etkin rol alabilir ya da fakültede düzenlenen toplantılarla özel okullarda çalışan BT öğretmenleri ile adaylar bir araya getirilerek gerekli bilgilendirme sağlanabilir.

Öte yandan, özel okulların başarısı; nitelikli, güdülenmiş ve başarılı öğretmenlerin o kurumlarda çalışması ve kurumların da öğretmenlerin gelişimlerini desteklenmesine bağlıdır (Whitaker ve Fiore, 2013). Bu da özel okullarda çalışan öğretmenlerin iş için güdülenmeleri, 
hissettikleri değer algıları, mesleki bağlılıkları ve mesleki doyumları gibi değişkenlerle doğrudan ilişkilidir (Khan ve diğerleri, 2017; Naidoo, 2019). Başka bir deyişle, öğretmenin niteliği veya öğretme deneyimi; güvenli bir çalışma ortamı, destekleyici yönetim ve ilgili veliler, yüksek düzeyde öğretmen memnuniyeti, güdülenmesi ve mesleki doyumu ile bağlantılı görülmektedir. BT öğretmenlerinin özel alan yeterlikleri ve teknoloji liderliği rolü düşünüldüğünde, yaşanılan teknolojik dönüşüm ve entegrasyon sürecinde okullardaki en yetkin öğretmenlerden biri olduğunu bilmesi, değerinin farkında olması, kurumsal destekle birlikte kendini ve kurumunu sürekli geliştirmesi son derece önemlidir. Unutulmaması gereken şudur ki, şu an kodlama, robotik ve STEM konuları sıklıkla tartışılmakta ve özel okullarda bu uygulamaları temel alan eğitimlere ve projelere daha fazla yer verilmektedir. Yarın bu teknolojiler ve uygulamalar değişse de yeni kullanılacak olan teknolojilerin eğitime kaynaştırılmasında da etkin rol alacak kişiler yine BT öğretmenleridir. Bu nedenle BT öğretmenlerinin hem devlet okullarında hem de özel okullarda sahip oldukları önemin ve gücün farkında olması gerekir.

Araştırmada öğretmenlerin sunduğu önerilerden yola çıkarak, özel okullarda daha az sorun yaşamak için BT öğretmenlerinin daha o kurumda çalışmaya başlamadan okul yönetimi ve velilerle ile karş11ıklı istek ve beklentileri netleştirmesinin faydalı olacağ düşünülmektedir. Bunun için süreç başında dönem içinde yapılacak etkinlikleri ve uygulamaları planlayabilir, okul yönetiminin de desteğini alarak kendilerini de geliştirmeye devam edebilir. Buna ek olarak, bu öğretmenlerin yaşadıkları sorunları araştıran, çözüm önerileri geliştiren ve onların güdülenmelerini, iş doyumlarını, değer algılarını ve mesleki bağlılıklarını araştıran çalışmalar yapılabilir. Böylece özel okullarda çalışan BT öğretmenlerinin güdülenmeleri, iş doyumları, yeterlik algıları ve mesleki bağl1lıkları nedenleri ile ortaya konulabilir, öneriler getirilerek profesyonelliğini etkili bir biçimde sürdürmeleri desteklenebilir.

Hansen’e (2017) göre eğitim kurumlarının başarısı öğretmenlerin beklentilerinin, isteklerinin, tanımladıkları iyi çalışma koşullarının ve onlar için iyi öğretimin ne anlama geldiğinin iyi bir biçimde çözümlenmesi ile olanaklıdır. Şüphesiz ki sürecin en başında yapılan iyi bir çözümleme ve yol haritası BT öğretmenlerinin uygulama şoku yaşamadan mesleklerini sürdürebilmelerine önemli katk1 sağlayacaktır.

Açıklamalar: Bu çalışmanın bir bölümü 2-4 Mayıs 2019 tarihinde Kırşehir'de gerçekleşen 13. Uluslararası Bilgisayar ve Öğretim Teknolojileri Eğitimi Sempozyumunda bildiri olarak sunulmuştur.

\section{Kaynaklar}

Akgün, Ö. E., Topal, M. ve Kıyıcı, M. (2019). Bir BÖTE lisans programının öğrencilerin mesleki yeterlikleri kazanmaları üzerindeki etkisinin incelenmesi. Yüksekögretim Dergisi, doi:10.2399/yod.19.010

Altun, E. ve Ateş, A. (2008). Bilgisayar ve öğretim teknolojileri öğretmen adaylarının sorunları ve geleceğe yönelik kaygıları. Illkögretim Online, 7(3), 680-692.

Atal-Köysüren, D. ve Deryakulu, D. (2017). Eğitim politikalarındaki değişimlerin bilişim teknolojileri öğretmenlerinin duyguları üzerindeki etkisi. Ĕgitim ve Bilim, 42(190), 67- 87.

Atmaca, T. (2020). Öğretmenlerin Yaptıkları Meslek Hatalarının Meslekî Öğrenme Bağlamında İncelenmesi. Ahi Evran Üniversitesi Sosyal Bilimler Enstitüsü Dergisi, 6 (1), 309-326. doi:10.31592/aeusbed.673360

Ballou, D. ve Podgursky, M. (1998). Teacher recruitment and retention in public and private schools. Journal of Policy Analysis and Management: The Journal of the Association for Public Policy Analysis and Management, 17(3), 393-417. 
Creswell, J. W. (2007). Qualitative inquiry and research design: Choosing among five approaches. California: Sage publications.

Creswell, J. W. (2011). Educational research: Planning, conducting, and evaluating quantitative. Upper Saddle River, NJ: Prentice Hall.

Çakır, H., Çebi, A. ve Özcan, S. (2013). BÖTE nedir? Nasıl tanımlanır? Okul müzesiyle başlayan serüvenden insan performans teknolojilerine uzanan yolculuk. Eğitim Teknolojisi Kuram ve Uygulama, 3(2), 102-111.

Correa, J. M., Martínez-Arbelaiz, A. ve Aberasturi-Apraiz, E. (2015). Post-modern reality shock: Beginning teachers as sojourners in communities of practice. Teaching and Teacher Education, 48, 66-74.

Day, C., Fernandez, A., Hauge, T. ve Moller, J. (Eds) (2000) The Life and Work of Teachers. London: Falmer Press.

Deryakulu, D. (2005). Bilgisayar Öğretmenlerinin Tükenmişlik Düzeylerinin İncelenmesi. Eurasian Journal of Educational Research (EJER), 19, 35-53.

Devolder, A., Vanderlinde, R., Van Braak, J. ve Tondeur, J. (2010). Identifying multiple roles of ICT coordinators. Computers \& Education, 55(4), 1651-1655ç

Dursun, F. ve Saracaloğlu, A. S. (2016). Bilişim teknolojileri öğretmenlerinin kendi yeterlikleri ve uygulamadaki sorunlar hakkındaki görüşlerinin değerlendirilmesi. The Journal of International Lingual Social and Educational Sciences, 2(2), 40-58.

Eren, E. ve Uluuysal, B. (2012). Bilişim teknolojileri (BT) öğretmenlerinin mesleki sorunları ve çözüm önerileri: Okul müdürü ve BT öğretmenlerinin görüşleri. Mersin Üniversitesi Ĕgitim Fakültesi Dergisi, 8(3), 152-171.

Green, F., Machin, S., Murphy, R. ve Zhu, Y. (2008). Competition for private and state school teachers. Journal of Education and Work, 21(5), 383-404.

Güneş, F. ve Uygun, T. (2016). Öğretmen yetiştirmede beceri uyuşmazlığı. Ahi Evran Üniversitesi Sosyal Bilimler Enstitüsü Dergisi, 2(3), 1-14.

Hansen, D. T. (2017). The teacher and the world: A study of cosmopolitanism as education. New York, NY: Routledge.

Hansen, D. T. (2017). The teacher and the world: A study of cosmopolitanism as education. London: Routledge.

Khan, F., Mateen, A., Hussain, B., Sohail, M., \& Khan, A. (2017). Factors affecting job turnover: A case study of private schools of District Swat. Sarhad Journal of Management Sciences, 3(01), 46-56.

Kyllonen, P. C. (2012, May). Measurement of 21st century skills within the Common Core State Standards. Paper presented at the Invitational Research Symposium on Technology Enhanced Assessments (TEA), Washington, DC.

Lai, K. W., \& Pratt, K. (2004). Information and communication technology (ICT) in secondary schools: the roles of the computer coordinator. British Journal of Educational Technology, 35, 461-465. 
Millî Eğitim Bakanlığ1 (2017), Öğretmen Yetiştirme ve Geliştirme Genel Müdürlügü, Öğretmenlik Mesleği Genel Yeterlikleri https://oygm.meb.gov.tr/www/ogretmenlik-meslegi-genelyeterlikleri/icerik/39 adresinden 21.12.2019 tarihinde ulaşılmıştır.

Milli Eğitim Bakanlığı, Personel Genel Müdürlüğü, Y1l ve Türlere Göre Taban Puanlar http://atama.meb.gov.tr/sonuclar/arsiv/sayisal_veriler.asp?k_yil=2013\&k_tur=2\&Sonuc=Gost er adresinden 18.12.2019 tarihinde ulaşılmıştır.

Naidoo, S. (2019). Factors affecting job satisfaction at a private school in Pietermaritzburg, KwaZuluNatal. The Independent Journal of Teaching and Learning, 14(1), 68-85.

Premalatha, D. S., \& Subramanian, S. (2020). An Empirical Relationship between Stress and Job Performance: A Study with Private School Teachers. EXECUTIVE EDITOR, 11(01), 57-60.

Rubie-Davies, C. M. (2017). Teacher expectations in education. New York, NY: Routledge.

Sönmezer, M. G. ve Eryaman, M. Y. (2008). A comparative analysis of job satisfaction levels of public and private school teachers. Journal of Theory \& Practice in Education (JTPE), 4(2),189-212.

Tondeur, J., Cooper, M. ve Newhouse, C. P. (2010). From ICT coordination to ICT integration: A longitudinal case study. Journal of Computer Assisted Learning, 26(4), 296-306.

Tosun, N. (2014). BÖTE bölümü öğrencilerinin proje tabanli topluma hizmet uygulamalari dersine ilişkin görüşlerinin incelenmesi. Kastamonu Eğitim Dergisi, 22(3), 961-980.

TTKB (2014). Öğretmenlik alanları, atama ve ders okutma esasları. 07.01.2020 tarihinde http://ttkb.meb.gov.tr/meb_iys_dosyalar/2019_11/14162856_9_cizelgeveesaslar.pdf adresinden erişilmiştir.

$\mathrm{Xu}, \mathrm{Z}$. ve Gulosino, C. A. (2006). How does teacher quality matter? The effect of teacher-parent partnership on early childhood performance in public and private schools. Education Economics, 14(3), 345-367.

Yeşiltepe, G. M. ve Erdoğan, M. (2013). İlköğretim Bilişim Teknolojileri Öğretmenlerinin Mesleğe Yönelik Sorunları, Bu Sorunların Nedenleri ve Çözüm Önerileri. Gazi University Journal of Gazi Educational Faculty (GUJGEF), 33(3),495-530.

Yükseköğretim Bilgi Yönetim Sistemi (2019). Yükseköğretim İstatistikleri, Öğrenim Düzeyleri ve Yüksek Öğretim Kurumlarının Birimlerine Göre Mezun Sayıları https://istatistik.yok.gov.tr/ adresinden 18.12.2019 tarihinde ulaşılmıştır.

Yükseköğretim Kurumu (1997). Türk Yükseköğretiminin Bugünkü Durumu, https://www.yok.gov.tr/Documents/Yayinlar/Yayinlarimiz/Turk-yuksekogretiminin-bugunkudurumu-kasim-1997.pdf adresinden 21.12.2019 tarihinde ulaşılmıştır. 


\section{Extended Abstract}

\section{Introduction}

With the restructuring of the Faculties of Education in 1997, the Department of Computer and Instructional Technology Education (CEIT) was established and teacher training was started in this department (YOK, 1997). Until 2016, approximately 43\% of these graduates were employed in the Ministry of National Education. However, it is noteworthy that there has been a radical decrease in the number of ICT teachers appointed in one year due to the changes in teacher appointment implementation of MoNE in 2017 and beyond. As a result of this employment problem, ICT teacher candidates started to find jobs in different professions. Even though they have different professions to work in, private schools provide an important employment opportunity especially for the ICT candidates who want to proceed their teaching profession. In this study, it is aimed to determine the duties and responsibilities of the ICT teachers who are graduate of CEIT and work in private schools, their expectations from the private schools and how they make sense of themselves as professional.

\section{Method}

In this research, qualitative research approach has been used. Teachers with similar prerequisites in different institutions and their common experiences were designed as case studies. Questionnaire was used as a data collection tool and it consisted of structured open-ended questions prepared by researchers. The data were analyzed by making descriptive analyzes. A total of 25 IT teachers participated in the study. 18 of these teachers are women (72\%) and 7 of them are men (28\%).

\section{Findings, Discussion and Results}

When the days and hours of ICT teachers working in private schools are examined, it is seen that more than half of the ICT teachers $(52 \%)$ work 6 days a week and 8 hours a day. About half of these teachers $(48 \%)$ receive a monthly salary of 3000 TL or less.It is noteworthy that more than half $(64 \%)$ of ICT teachers are employed as ICT teachers in schools, but they are also hired as ICT coordinator teachers $(24 \%)$ or software and robotics coding teachers $(12 \%)$. On the other hand, these teachers mostly enrolled in Information Technologies and Software course (BTY) in schools (88\%), as well as Robotics and Coding course (28\%), Computer Science course (12\%), Democracy and Human Rights course (4\%) and Technology Design course (4\%).

It has been determined that ICT teachers define themselves as teachers $(72 \%)$ who teach coding and robotic applications in schools and teachers who teach conscious, proper and effective use of ICT (60\%). On the other hand, apart from teaching profession, there are also teachers who consider themselves as intermediate staff (28\%), technical responsible (24\%), project manager (20\%). It seems that the duties and responsibilities of IT teachers are not limited to the wishes and expectations of school management and other teachers. The wishes and expectations of parents and students also increase their duties and responsibilities.

When the problems of these ICT teachers were analyzed, it is seen that they want to work elsewhere due to the problems and demands of parents who sent their children to private school (32\%), lack of equipment in the institution (16\%), and not being able to feel themselves as teachers in their institutions. In addition, many ICT teachers tend to seek another job, due to high workloads (76\%), duties and responsibilities unrelated to the profession (72\%) and low salaries (60\%). At the end of the research, ICT teachers made some suggestions to ICT teacher candidates who want to work in private schools. These are; keeping track of the changes in the field (60\%), being aware of the difficulty of working conditions in private school (48\%), preparing / improving themselves well before starting the profession (36\%), determining all their duties and responsibilities with school administrators before starting to work in the private school (32\%). 
It is known that private schools differ considerably from public schools in such dimensions such as working conditions, employment patterns, opportunities offered to students and teachers, and expectations from teachers. According to Green et al. (2008), teachers who want to work in a private school should have some sector-specific awareness and skills. According to the research, ICT teacher in private school seen as a professional who,

- has different and actual subject / content information,

- has proficiency in teaching these subjects and contents,

- constantly improving himself/herself,

- has responsibilities for the design and implementation of extracurricular activities / courses / projects on these current issues,

- can also be employed for other positions such as Software and Coding or STEM teaching besides IT teaching,

- is working under intense workload and working conditions

- has sufficient technical facilities and teaching lessons in non-crowded classrooms,

- meets the expectations of parents as well as the expectations of the school management,

- and who are unable to achieve achieve sufficient financial and / or moral satisfaction.

When all these problems experienced by ICT teachers working in private schools, the lessons they teach, the projects they carry out and other responsibilities are taken into consideration, it is obvious that working in private school it is not easy for ICT teachers. At this point, it is thought that the candidates need awareness and support during the teacher education process. Although new technologies and practices change in the future, ICT teachers who will take an active role in the integration of new technologies to education. For this reason, ICT teachers need to be aware of the importance and power they have in both public and private schools. 